\section{Staphylococcus aureus colonization on antecubital non-exacerbated atopic dermatitis patient compared to healthy children}

\author{
Nur Khamidah, Evy Ervianti, \\ Hari Sukanto \\ Dermatovenereology Departement \\ Medical Faculty of Airlangga \\ University/Dr. Soetomo General \\ Hospital Surabaya, East Java, Indonesia
}

\begin{abstract}
Atopic dermatitis is chronic pruritic inflammatory skin disease affects one third of children in the world, and the highest number of child's skin problems in Indonesia. The complex role of the skin microbiome in the pathogenesis of atopic dermatitis is being elucidated. Interaction between skin barrier defects, and immunological factors can change the skin microbiome, and increased Staphylococcus aureus colonization. The aim of this study was to compare the colony of Staphylococcus aureus from antecubital fossa of non-exacerbated atopic dermatitis children to healthy children without history of atopic dermatitis. A comparative observational analytic with cross sectional design, examined antecubital swab culture from 17 non-exacerbated atopic dermatitis patients and 17 controls to investigate the presence of Staphylococcus aureus and density of the colonization. Staphylococcus aureus skin colonization was seen in 5 patients $(29.41 \%)$ in non-exacerbated atopic dermatitis patients but none in control group (statistically significant with $\mathrm{p}=0.044$ ), relative risk 2.417 . All of positive colonization revealed moderate and heavy bacterial growth $\left(10^{4}->10^{5} \mathrm{cfu} / \mathrm{cm}^{2}\right)$. This finding supports previous study that atopic dermatitis prone to colonized with Staphylococcus aureus.
\end{abstract}

\section{Introduction}

Atopic dermatitis is a common skin disease that can cause major issues either physical, psychological, also financial due to the need for continuous and lengthy treatment, decreased quality of life because of itchy sensation, and the demand for lifestyle changes. ${ }^{1,2}$ Epidemiological data shows that atopic dermatitis is more common in children, about $15-30 \%$, while only $2-10 \%$ in adults. The reported prevalence of atopic dermatitis in Hong Kong is $20.1 \%$, Japan $19 \%$, and Singapore $20.8 \%{ }^{3}$ Atopic dermatitis prevalence in Pediatric Dermatology Division of Outpatient Unit of Dermatovenerology department of Dr. Soetomo General Hospital, Surabaya was recorded at $12.16 \%$. Eventhough the prevalence is less than other country, but still first ranked of ten skin disease in children. ${ }^{4}$

The skin flora and its density in patients with atopic dermatitis is strikingly different from that of healthy people. Defects in the skin barrier function, decreased antibacterial activity in innate and adaptive immunity, also imbalances in immune response suspected as part of atopic dermatitis's pathogenesis which probably increased colonization of microorganisms (viruses, bacteria or fungi) on the patient's skin. Staphylococcus aureus is the most virulent and pathogenic species from said genus, which can affect the body's condition. Direct colonization or through its products such as toxins, proteins, or enzymes, can lead aggravate the clinical lesional and may induce exacerbations of atopic dermatitis. ${ }^{5,6}$ Several studies have discussed the presence of Staphylococcus aureus only on exacerbated atopic dermatitis patients's skin, comparing the lesional skin area to the non-lesion area (at a distance of several centimeters from the edge of the lesion), or comparing atopic dermatitis lesion with the normal skin of the control patients. This study aims to determine the comparison of colonization of Staphylococcus aureus in the antecubital fossa of children with non-exacerbated atopic dermatitis and skin of healthy children with no history of atopic dermatitis.

\section{Materials and Methods}

This was an analytic observational study with cross sectional design in the Dermatovenereology Outpatient Unit of Dr. Soetomo General Hospital, Surabaya from July-August 2017. Research subjects were children who have been diagnosed with atopic dermatitis in the Pediatric Dermatology division of the Dermatovenereology Outpatient Unit in Dr. Soetomo General Hospital, Surabaya; aged 2-12 years; and has not experienced an exacerbation for at least 8 weeks. Controls subjects were all healthy non-atopic dermatitis children, aged 2-12 years. Exclusion criteria were patients taking corticosteroids and/or oral antibiotics for the past 4 weeks, topical in the last 2 weeks; patients are suffering from other immunosuppressed diseases that can increase the risk of bacterial
Correspondence: Nur Khamidah, Dermatovenereology Departement, Dr. Soetomo General Hospital, Prof. Dr. Moestopo No.47, Surabaya, East Java, Indonesia.

Tel.: +6281252000024.

E-mail: midul_mbem@yahoo.com

Key words: atopic dermatitis, Staphylococcus aureus, colonization.

Acknowledgments: This study was supported by Dr. Soetomo General Hospital/ Medical Faculty of Airlangga University Surabaya

Contributions: Contribution materials: NK, EE, HS; Wrote the paper: NK, EE, HS; Data collection: NK.

Conflict of interest: There are no potential conflict of interest relevant to this study.

Funding: None.

Received for publication: 1 February 2019. Accepted for publication: 13 February 2019.

This work is licensed under a Creative Commons Attribution-NonCommercial 4.0 International License (CC BY-NC 4.0).

(C) Copyright N. Khamidah et al., 2019 Licensee PAGEPress, Italy

Dermatology Reports 2019; 11(s1):8058 doi:10.4081/dr.2019.8058

infections such as diabetes, malignancy, HIV-AIDS and others; patients with other skin diseases which has other complaints or lesions in the area to be examined. Informed concent was obtained from the parents of suitable patients. All the patients were subjected to: history taking (name, age, sex, frequency of flare, last remision, history of other atopy disease of the patients and the family, history of used skin moisturizer) and clinical examination (xerosis of the skin). Skin swabs were collected from right antecubital fossae from patients with non-exacerbated atopic dermatitis and also from healthy controls. The swabs were first dipped in sterile saline and an area of skin 1 $\mathrm{cm}^{2}$ in area was rubbed for $30 \mathrm{~s}$. Swabs were incubated on CHROMagar ${ }^{\mathrm{TM}}$ Staphylococcus aureus at $37{ }^{\circ} \mathrm{C}$ for $24-48$ hours. Staphylococcus aureus are identified by mauve colonies, positive coagulase test and positive catalase test. Density of Staphylococcus aureus classified as none, light $\left(<10^{4} \mathrm{cfu} / \mathrm{cm}^{2}\right)$, moderate $\left(10^{4}-10^{5}\right.$ $\left.\mathrm{cfu} / \mathrm{cm}^{2}\right)$ and heavy $\left(>10^{5} \mathrm{cfu} / \mathrm{cm}^{2}\right)$ as criteria from Hon et al. ${ }^{8}$ Data then analyzed by using chi square test analysis. Ethical clearance had been approved for this study by the Ethical Committee in the hospital. 


\section{Results}

A total of 34 patients were examined. From 17 non-exacerbated atopic dermatitis patients and 17 control patients, homogeneity was observed in both groups from age, sex, history of moisturizer usage, and other history of atopy in patients. On the other hand, dry skin conditions and history of atopy in the patient's family appear to differ significantly between atopic dermatitis groups and controls (Table 1).

Colonization of Staphylococcus aureus bacteria was obtained in 5 non-exacerbated atopic dermatitis patients $(29.41 \%)$ whereas none was found in control patients, which was statistically significant with a $p$ value of 0.044 . The relative risk of colonization of Staphylococcus aureus in the skin of nonexacerbated atopic dermatitis patients compared to healthy skin of healthy non-atopic dermatitis children was 2.417 (Table 2). The five patients with has positive cultures results showed moderate to large colony densities, one patient with $3.3 \times 10^{4} \mathrm{cfu} / \mathrm{cm}^{2}$, one with $5.5 \times 10^{4} \mathrm{cfu} / \mathrm{cm}^{2}$, and 3 patients with $>10^{5} \mathrm{cfu} / \mathrm{cm}^{2}$.

\section{Discussion}

The skin is colonized by various microbial species which together form a microbiom. These compositions vary between individuals, and the location of skin topography. ${ }^{7-9}$ The skin served a complex barrier organ made of a symbiotic relationship between microbial communities and host tissue via complex signals provided by the immune systems. It is constantly exposed to various endogenous and exogenous factors which impact this balanced system. Several disease showed alterations in the skin microbiome, lead to increased pathogen invasion such as bacteri. ${ }^{5}$

Skin barrier disruption in atopic dermatitis patients will lead to massive exudation of plasma proteins and may serve as a molecular glue that facilitates the attachment of Staphylococcus aureus to the skin. After the initial attachment of Staphylococcus aureus to the atopic skin, homeostasis is achieved between host cells and bacteria. Bacteria will be able to enter through keratinocyte destruction or can be embedded in the curvature of the cell surface which will then also be followed by damage to keratinocyte cells. Keratinocyte damage can occur directly or indirectly due to alpha hemolytic toxin produced by Staphylococcus aureus which causes keratinocyte cell death through the formation of holes in keratinocyte cell membrane. Staphylococcus aureus is easier to stick to inflamed atopic skin. ${ }^{10}$ In this study, a positive culture of Staphylococcus aureus was obtained in $29.41 \%$ of non-exacerbated atopic dermatitis patients. This result is similar to previous studies with a study sample of exacerbated atopic dermatitis patients which examined non-lesion areas defined as areas with a certain distance from the edge of the lesion in the same region with atopic dermatitis lesions, e.g. a study by Gomes in $2010(32 \%)^{11}$, Thakur in $2013(22 \%)^{12}$, Alenizi $2014(30 \%)^{7}$, Hon in $2015(56.8)^{8}$ and $2016(55 \%)^{13}$. In the control group, none of the children had colonization of Staphylococcus aureus. Gomes in 2010 found that $8 \%$ of control patients had colonization of Staphylococcus aureus on their skin, while Alenizi research in 2014 found that $13.33 \%$ of healthy child skin had colonization of Staphylococcus aureus..$^{7,11}$

The skin of atopic dermatitis patients is particularly susceptible to colonization of Staphylococcus aureus given the barrier defects and immunity that occur, but this study found only about one-third of atopic dermatitis patients who are not exacerbated who have colonization of Staphylococcus aureus in their antecubital areas. This is probably due to the fact that Staphylococcus aureus may colonize the human skin intermittently, which makes it undetectable during examination in the outpatient unit. The second possibility is the amount of damage to the skin barrier and the immunity experi-

Table 1. Characteristics of Patients Study.

\begin{tabular}{|c|c|c|c|}
\hline Characteristics & Atopic dermatitis & Control & P value \\
\hline Age & $5.94 \pm 2.94$ & $5.94 \pm 2.90$ & 1.000 \\
\hline $\begin{array}{l}\text { Gender } \\
\text { Male } \\
\text { Female }\end{array}$ & $\begin{array}{c}7(41.2 \%) \\
10(58.8 \%)\end{array}$ & $\begin{array}{c}7(41.2 \%) \\
10(58.8 \%)\end{array}$ & 1.000 \\
\hline $\begin{array}{l}\text { Other atopy disease on patients } \\
\text { Yes } \\
\text { No }\end{array}$ & $\begin{array}{c}3(17.65 \%) \\
14(82.35 \%)\end{array}$ & $\begin{array}{c}3(17.65 \%) \\
14(82.35 \%)\end{array}$ & 1.000 \\
\hline $\begin{array}{l}\text { History atopy disease on family } \\
\text { Yes } \\
\text { No }\end{array}$ & $\begin{array}{c}15(88.2 \%) \\
2(11.8 \%)\end{array}$ & $\begin{array}{c}4(23.5 \%) \\
13(76.5 \%)\end{array}$ & 0.001 \\
\hline $\begin{array}{l}\text { Use of daily moisturizer } \\
\text { Yes } \\
\text { No }\end{array}$ & $\begin{array}{c}4(23.5 \%) \\
13(76.5 \%)\end{array}$ & $\begin{array}{c}2(11.8 \%) \\
15(88.2 \%)\end{array}$ & 0.656 \\
\hline $\begin{array}{l}\text { Xerosis cutis } \\
\text { Yes } \\
\text { No }\end{array}$ & $\begin{array}{c}17(100 \%) \\
0(0)\end{array}$ & $\begin{array}{c}3(17.6 \%) \\
14(82.4 \%)\end{array}$ & 0.000 \\
\hline
\end{tabular}

Table 2. Presence of Staphylococcus aureus on Antecubital Patients Study

\begin{tabular}{lccccc} 
& Atopic dermatitis + & Atopic dermatitis - & P value & RR \\
Staphylococcus aureus + & 5 & 0 & 0.044 & 2.417 \\
Staphylococcus aureus - & 12 & 17 & & \\
\hline Total & 17 & 17 & &
\end{tabular}

enced by each atopic dermatitis patient is different, giving rise to different potential vulnerabilities. ${ }^{7,14,15}$

The relative risk (RR) of colonization of Staphylococcus aureus on the healthy skin of atopic dermatitis patients obtained in this study was 2.417 , which means that in healthy skin of patients with non-exacerbated atopic dermatitis has $2.4 \mathrm{x}$ the risk of colonization of Staphylococcus aureus compared to healthy skin of non-atopic dermatitis patients. Other studies have shown similar results. Another study in the same year by Hon and colleagues showed RR of 2.16; Tauber and his colleagues got RR 2,3. ${ }^{8,13}$

\section{Conclusions}

From this study it could be seen that colonization of Staphylococcus aureus was found more in the skin of non-exacerbated atopic dermatitis patients compared to the skin of healthy children without atopic dermatitis, which was statistically significant. This supports the hypothesis that healthy skin of atopic dermatitis patients, although clinically well, might be more prone to bacand skin immunity. Hence, patients and their family need to be educated about the importance of skin care to minimize the effects that can be caused from the defect barrier and immunity. terial colonization due to defects in barrier 


\section{References}

1. Eichenfield LF, Tom WL, Chamlin SL, Feldman SR, Hanifin JM, Simpson EL. Guidelines of care for the management of atopic dermatitis Section 1. Diagnosis and assessment of atopic dermatitis. J Am Acad Dermatol 2014; 70 : 338-51.

2. Kim JP, Chao LX, Simpson EL, Siverberg JI. Persistence of atopic dermatitis (AD): A systematic review and meta analysis. J Am Acad Dermatol; 75(4): 681-7.

3. Bieber T. Atopic dermatitis. Ann Dermatol 2010; 22(2): 125-37.

4. Thohiroh A, Zulkarnain I. Penggunaan kortikosteroid pada anak dengan dermatitis atopik. BIKKK 2012; 24(2): 140-6.

5. Powers CE, Mcshane DB, Gilligan PH, Burkhart CN, Morrel DS. Microbiome and pediatric atopic dermatitis. J Dermatol 2015; 42: 1137-42.

6. Petry V, Bessa GR, Poziomczyck CS,
Oliveira CF, Weber MB, Bonamigo RR, et al. Bacterial skin colonization and infections in patients with atopic dermatitis. An Bras Dermatol 2012; 87(5): 729-34.

7. Alenizi DA. Prevalence of Staphylococcus aureus and antibiotic resistance in children with atopic dermatitis in Arar, Saudi Arabia. Journal of Dermatology and Dermatologic Surgery 2014; 18: 22-6.

8. Hon KL, Tsang YC, Pong NH, Leung F. Clinical features and Staphylococcus aureus colonization/infection in childhood atopic dermatitis. J Dermatol Treat 2015; 20: 1-6.

9. Williams MR, Gallo RL. The Role of the Skin Microbiome in Atopic Dermatitis. Curr Allergy Asthma Rep 2015; 15: 1-11.

10. Mempel M. Staphylococcus and atopic dermatitis. J Dermatol 2012; 65: 406-9.

11. Gomes PLR, Malavige GN, Fernando N, Mahendra MHR, Kamaladasa SD, Seneviratne JKKm et al. Characteristics of Staphylococcus aureus colonization in patients with atopic dermatitis in Sri Lanka. Clin Exp Dermatol 2010; 36: 195-200.

12. Thakur A, Malhotra S, Malhotra SK. Bacteriological profile in atopic dermatitis: comparison between normal and lesional skin. J of Pakistan Ass Dermatol 2013; 23 (4): 360-4.

13. Hon KL, Tsang YC, Pong NH, Leung F. Exploring Staphylococcus epidermidis in atopic eczema: friend or foe? Clinical and Experimental Dermatology 2016; 41: 659-63.

14. Wertheim HFL, Melles DC, Vos MC, Leeuwen WV, Belkum AV, Verbrugh $\mathrm{HA}$, et al. The role of nasal carriage in Staphylococcus aureus infections. Lancet Infect Dis 2005; 5: 751-62.

15. Sollid JUE, Furberg AS, Hanssen AM, Johannessen M. Staphylococcus aureus: Determinants of human carriage. Infect Genet Evol 2014; 21: 531-41. 